\title{
RESEARCH AND APPLICATION OF PRECISION FERTILIZATION ON MAIZE
}

\author{
Helong $\mathrm{Yu}^{1,2, *}$, Guifen Chen ${ }^{1,2}$, Dayou liu ${ }^{1}$ \\ ${ }^{1}$ College of Computer Science and Technology, Jilin University, Changchun,Jilin Province, \\ P. R. China, 130012 \\ ${ }^{2}$ College of information Technology, Jilin Agricultural University, Changchun, Jilin Province, \\ P. R. China 130118 \\ * Corresponding author, Address: College of Computer Science and Technology,Jilin \\ University, Changchun, Jilin Province, P. R. China, 130012,Tel: +86-431-84556016, Fax: \\ +86-431-84532775, Email:yuhelong@yahoo.com.cn
}

\begin{abstract}
The current precision fertilization technology of maize is still incomplete and unsystematic. In the paper, according to the fact of maize production of black soil zone in Jilin province, spatial variability of soil nutrient is studied, precision fertilization model of maize is introduced, a web-based expert system for maize precision fertilization is developed. Finally, the precision fertilization is implemented by the variable rate fertilizer. The practice shows that, by the program proposed in this paper, the maize yield was increased by nearly $10 \%$, and the fertilizer was saved about $10.5 \%$.Furthermore ,the profit and maize quality was increased and the environmental pollution and input cost was decreased.
\end{abstract}

Keywords: maize, precision fertilization, spatial variability, expert system

\section{INTRODUCTION}

Precision fertilization is the key part of precision agriculture. The implementation of precision fertilization can Save fertilizer, increase food production(GAO Xiang-zhao, HU Ke-lin,etc.2002) and balance soil nutrients (Zhang Shuhui, Ma Chenglin, Li We i, Xu Yan,etc.2006). Maize is China's important food crops. Black soil area in Jilin Province is the prime maize

Please use the following format when citing this chapter:

Yu, H., Chen, G. and Liu, D., 2009, in IFIP International Federation for Information Processing, Volume 293, Computer and Computing Technologies in Agriculture II, Volume 1, eds. D. Li, Z. Chunjiang, (Boston: Springer), pp. 477-486. 
growing areas. Precision fertilization is of great significance for black soil area in Jilin Province to reduce fertilizer inputs, increase maize production and improve maize quality.

The key technologies of Precision fertilization include the following three points. Firstly, it should be based on the spatial variation of soil nutrients to implement the accuracy of soil nutrient testing and crop nutrients diagnosing. Secondly, appropriate fertilization model should be determined to implement the precision of fertilizer amount. Thirdly,good fertilization machines should be selected to implement variable rate fertilization.

Spatial variation analysis of soil nutrients is the basis of precision fertilization, the aim of which is to determine management zones. There are three methods to determine management zones, which are cluster analysis, primary component analysis and space variation coefficient(Rodrigo A,Ortega,etc.2007).

In the research and practice of recommended fertilization for crop, there are as many as over 60 kinds of fertilizer model. However, there exist many contradictions between these fertilizer models and the current production practice. Also, large amounts of accumulated data can't be used to direct the production practice( Hou yanlin, Chen shoulun.2004).

In the fertilization practice, there are still a lot of uncertainty and complexity, which indicates that the experience of agricultural domain experts is essential.

So, how to combine the experience of human expert and fertilization model is very important. Fortunately, an expert system about maize precision fertilization was developed, which can solve the above problem effectively. In the future, the expert system will be distributed and serviceoriented (Edson Murakami,Antonia M.Saraiva,et al.2007).

\section{TECHNICAL ROUTES OF MAIZE PRECISION FERTILIZATION}

Maize precision fertilization is composed of four steps: data collection, analysis of soil spatial variation, determination of fertilization model and application of precision fertilization. The detail is as follows:

\section{(1) Data collection}

(1) Sampling nutrient data and yield data by GPS and sensor

(2) Grid plotting by GIS

(3) Sampling, analyzing and testing of soil

(2)Data Analysis

(1)Building the spatial database and attribute database 
(2)Plotting spatial variation map of soil nutrient, exploring the spatial variation law

(3)Determining and optimizing the sampling mode and layout

(3) selection of fertilization model

(1)Evaluating and preferring existing model

(2)Fertilization model fusion

(3)Determination of appropriate fertilization model

(4) Application of precision fertilization

(1)Developing precision fertilization expert system

(2)Import the fertilization prescription into the field computer

(3)Implementing the precision fertilization

\section{DATA COLLECTION}

The experimental Field is located in Gongpeng town, one town of Yushu City in Jilin, which is typical of the black soil zone.

In the experimental site, the perimeter of the area of study was demarked with DGPS。The area of the experimental field is $17 \mathrm{hm}^{2}$. The sampling grid is $40 \mathrm{~m} \times 40 \mathrm{~m}$ and 105 samples were achieved. Fig. 1 is the grid map of the experimental site. After soil sampling, the soil NPK was tested by chemical method.

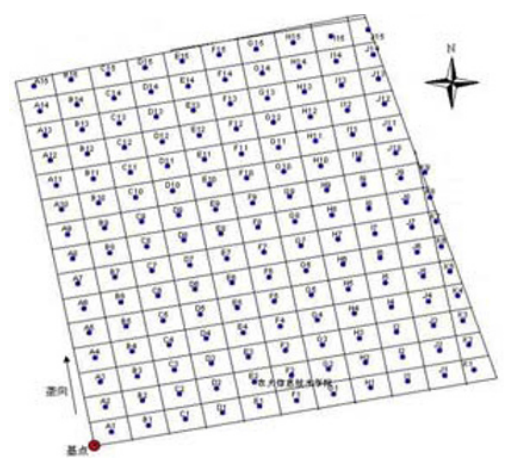

Fig.1 The grid map of the experimental site.

\section{THE SPATIAL VARIABILITY ANALYSIS OF THE SOIL NUTRIENT}

The spatial variability analysis is based on two methods. One is conventional statistics, which can provide basis for determining the number 
of samples and the grid layout. The other is geo-statistics analysis, which can provide basis for precision fertilization and management zones(Zhang Shujuan, He Yong, Fang Hui.2003) .

\subsection{Conventional statistics}

The parameters based on conventional statistics can be seen from table 1.It shows that the spatial variation of $\mathrm{P}$ is the largest and the C.V(coefficient of variation)is $52.86 \%$; The spatial variability of $\mathrm{N}$ an $\mathrm{K}$ is small and the C.V is $9.6 \%$ and $5.99 \%$ respectively. According the above results and the fertilizer need of maize in seedling stage, we can conclude that the variable rate fertilization of maize in black soil area is mainly variable rate of $P$.

Table 1. The statistics value of soil nutrient content

\begin{tabular}{cccccccc}
\hline Item & Minimum & Maximum & Mean & S.D. & Skewness & Kurtosis & C.V. (\%) \\
\hline $\mathrm{N}\left(\mathrm{mg} \cdot \mathrm{kg}^{-1}\right)$ & 90.8 & 175.6 & 114.485 & 10.992 & 0.740 & 0.573 & 9.60 \\
$\mathrm{P}\left(\mathrm{mg} \cdot \mathrm{kg}^{-1}\right)$ & 10.55 & 415.20 & 49.6952 & 26.2706 & 7.454 & 83.789 & 52.86 \\
$\mathrm{~K}\left(\mathrm{mg} \cdot \mathrm{kg}^{-1}\right)$ & 95 & 182 & 156.80 & 9.39 & -1.301 & 3.652 & 5.99 \\
\hline
\end{tabular}

\subsection{Geo-statistics analysis}

By model fitting for nutrient data and Cross-Validation for parameter revision, with ArcGIS, Optimal semi-variogram theoretical model and its parameters were achieved (Table 2).

Table 2. Semi-variation model and some parameters in the experimental field

\begin{tabular}{cccccc}
\hline Variables & Fitting model & Nugget & Partial Sill & Range $(\mathrm{m})$ & Nugget/Sill(\%) \\
\hline $\mathrm{N}$ & Pentaspherical & 22.998 & 38.987 & 291.63 & 37.10 \\
$\mathrm{P}$ & Exponential & 0.092 & 0.131 & 405.42 & 41.21 \\
$\mathrm{~K}$ & Hole Effect & 27.372 & 15.829 & 355.95 & 63.36 \\
\hline
\end{tabular}

From Table 2,we can see that spatial correlation of $\mathrm{N}$ and $\mathrm{P}$ is relatively high, and yet $\mathrm{K}$ is low. The variation of the range of soil nutrient content is not large, varying from $226.66 \mathrm{~m}$ to $405.42 \mathrm{~m}$, and the range of $\mathrm{P}$ is the largest, which is $405.42 \mathrm{~m}$.

By Ordinary Kriging method in Geo-statistics, The spatial variability map of NPK can be achieved(Fig.2). 


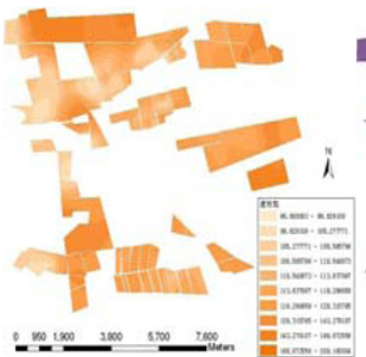

(a) $\mathrm{N}$

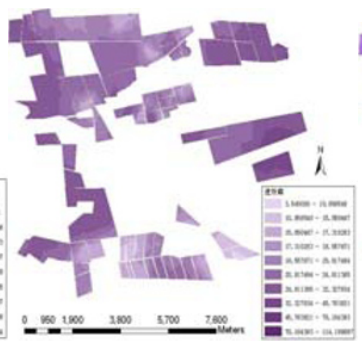

(b) $\mathrm{P}$

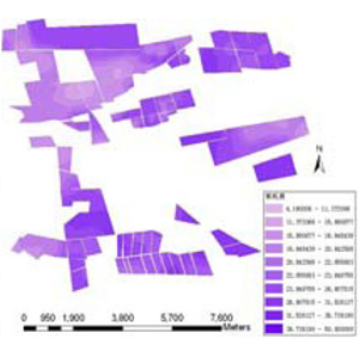

(c) $\mathrm{K}$

Fig.2 Spatial variability map of NPK

\section{THE DETERMINATION OF FERTILIZATION AMOUNT}

\section{$5.1 \quad$ Fertilization scheme}

Precision fertilization for maize is divided into two phases, namely subsoil fertilizer and additional fertilizer phase. Subsoil fertilizer amount is achieved by the optimization and fusion of the existing fertilizing model and based on soil nutrient。Additional fertilizer amount is achieved by crop nutrient diagnosis based on remote sensor.

According to the character of maize's growth and development, In the subsoil fertilizer phase, $\mathrm{N}$ and $\mathrm{P}$ should be fertilized when the maize growth is during seedling period. In the additional fertilizer phase, $\mathrm{N}$ should be fertilized when the maize growth is metaphase. Obviously, $\mathrm{N}$ is fertilized in the two phases. $\mathrm{N}$ fertilizer amount of seedling period mainly comes from subsoil compound fertilizer which includes a part of $\mathrm{N}$. According to the expert experience, the need of $\mathrm{N}$ of spring maize during seedling stage is approximately $30-50 \mathrm{~kg} / \mathrm{hm}^{2}$, fortunately, which is nearly the same as the $\mathrm{N}$ amount contained in subsoil compound fertilizer. So, in subsoil fertilization phase, the main task is to compute the $\mathrm{P}$ amount.

\subsection{The determination of subsoil fertilizer amount}

Fertilizer amount can be determined by three steps. Firstly, method of soil fertility indicators was used to achieve the range of fertilizer amount. Secondly, according to the level of variety liking fertilizer, another range of fertilizer amount was achieved; Thirdly, by the nutrient balance formula, the concrete fertilizer amount is computed, then taking soil fertility 
indicators and level of variety liking fertilizer into account, the final fertilizer amount is determined.

(1) Determining the range of fertilizer amount by the method of soil fertility indicators

According to the soil testing and fertilizer recommendations in Jilin province and the initial result of "3414"experiment, P level in the black soil was classified(Table 3 )。

Table 3. The level of $\mathrm{P}$ and corresponding fertilization amount in experimental field

\begin{tabular}{cccc}
\hline $\mathrm{P}(\mathrm{mg} / \mathrm{kg})$ & $6 \sim 19$ & $19 \sim 27$ & $>27$ \\
\hline Fertilizer amount with maximum yield $(\mathrm{kg})$ & $76 \pm 17$ & $70 \pm 14$ & $66 \pm 17$ \\
Fertilizer amount with economic optimum $(\mathrm{kg})$ & $64 \pm 12$ & $55 \pm 18$ & $57 \pm 15$ \\
\hline
\end{tabular}

(2) Providing reference for determination of fertilization amount by the attribute of maize needing fertilizer

As for the different maize variety, there exists much difference in the need for fertilizer(Xie Jia-gui, Wang Li-chun, etc.2006).According to coefficient of fertilizer absorption and coefficient of fertilizer effect, level of maize liking fertilizer can be divided into three grades, which are high, medium and low. Each level has its corresponding fertilizer amount with economic optimum(Table 4)

Table 4. The degree of maize response to nutrient and corresponding fertilization amount

\begin{tabular}{lccccccccc}
\hline \multicolumn{1}{c}{ Response degree } & \multicolumn{3}{c}{ High } & \multicolumn{3}{c}{ Middle } & \multicolumn{3}{c}{ Low } \\
\hline Fertilizer category & $\mathrm{N}$ & $\mathrm{P}$ & $\mathrm{K}$ & $\mathrm{N}$ & $\mathrm{P}$ & $\mathrm{K}$ & $\mathrm{N}$ & $\mathrm{P}$ & $\mathrm{K}$ \\
Fertilization amount $\left(\mathrm{kg} / \mathrm{hm}^{2}\right)$ & $225 \pm 25$ & $85 \pm 20$ & $110 \pm 20$ & $190 \pm 25$ & $70 \pm 20$ & $90 \pm 20$ & $165 \pm 25$ & $60 \pm 20$ & $80 \pm 20$ \\
\hline
\end{tabular}

\section{(3) Determining the fertilizer amount of each grid by soil nutrient balance formula}

The nutrient balance formula is as follows: $\mathrm{F}=(\mathrm{Y} \times \mathrm{C}-\mathrm{S}) /(\mathrm{N} \times \mathrm{E})$

In which, $\mathrm{F}$ : fertilization amount $\left(\mathrm{kg} / \mathrm{hm}^{2}\right) ; \mathrm{Y}$ : target $\operatorname{yield}\left(\mathrm{kg} / \mathrm{hm}^{2}\right)$; C: nutrients absorption of unit yield $(\mathrm{kg})$; S: Supply of nutrients in the soil $\left(\mathrm{kg} / \mathrm{hm}^{2}\right) ; \mathrm{N}$ : nutrient ratio in the fertilizer(\%); E: Quarter utilization rate of fertilizer $(\%) ; S=$ value of soil nutrients $\times$ Soil nutrient conversion factor 。

In order to use this formula, the key is to determine the value of parameters, which is achieved by the actual production situation and the results of previous studies.

According to the actual situation in the field, the target yield was set 8500 $\mathrm{kg} / \mathrm{hm}^{2}$; other parameters as follows: phosphorus absorption capacity of 100 kilograms of maize grain is 1.15 kilograms; phosphorus conversion factor is $1 /(0.1674+0.03579 \times$ value of phosphorus $) \times 1.5$; the $\mathrm{P}_{2} \mathrm{O}_{5}$ ratio in the 
compound fertilizer is $18 \%$; quarter utilization rate of fertilizer in black soil is $20 \%$ 。

By this formula, the fertilizer amount can be computed.

\section{(4) The determination of additional fertilizer amount}

As we have discussed, in the additional fertilizer stage, the fertilizer used is $\mathrm{N}$. The amount of $\mathrm{N}$ can be achieved by two methods. One method is to compute total $\mathrm{N}$ by nutrient balance formula, then the amount of additional $\mathrm{N}$ fertilizer is the total $\mathrm{N}$ minus the amount of subsoil $\mathrm{N}$ fertilizer. The other method of computing additional $\mathrm{N}$ fertilizer is by plant nutrient diagnosis, which takes into account the real time state of maize growing, so the computed fertilizer amount by this method is more precise. However, as far as the cost is concerned, the first method is adopted in this paper.

\section{THE APPLICATION OF PRECISION FERTILIZATION ON MAIZE IN BLACK SOIL AREA}

\subsection{The implementation of web-based expert system for maize precision fertilization}

The function of expert system is to achieve fertilization prescription. A PC-based fertilizer expert system has been developed (CHEN Gui-fen, WANG Yue, WANG Guo-wei.2006). In order to make user access the expert system through internet and alleviate the burden of the client computer, we developed a web based expert system, which is composed of seven modules: production forecasts, variety selection, rational fertilization, profit analysis, advisory printing, data statistics and maintenance.

Database, knowledge base and model base are core of the expert system, in which, knowledge base and model base extract data from database and cope with each other to give fertilizer recommendation.

In the knowledge base, rule-based knowledge representation was used, its form is as follows:

IF (condition 1) \& (condition 2) ...... THEN (conclusion)

This is a production rule, in which, the IF clause is called premise, the THEN cause is called consequences o The advantage of using production rule to represent agricultural knowledge is that it has simple form and strong representation capacity and can be understood easily. 
The model base in the web based expert system mainly includes the following fertilization models: nutrient balance model, fertilizer response function model, nutrient abundant index model and the property of maize liking nutrient model. The developer or the user can choose different model according to the actual situation.

\subsection{Fertilization amount recommendation and implementation of precision fertilization}

Fertilization prescription map can be achieved by expert system, then it will be imported into the variable rate fertilization machine.

The variable rate fertilization machine adopted in this experiment is adapted by suction seeder, and is of dual function of precision seeding and precision fertilizing. In order to implement the precision fertilization, a field computer is adopted in this machine to control the fluid power system directly (QU Gui-bao,TIAN-yun.2005).

Fluted roller feed distributor is adopted to implement the fertilizer distribution. The range of variable rate fertilization is $0 \sim 675 \mathrm{~kg} / \mathrm{ha}$, the precision of which is $5 \sim 10 \%$ and the working width is $3 \sim 5 \mathrm{~m}$. The operating principle can be seen in Fig.3.

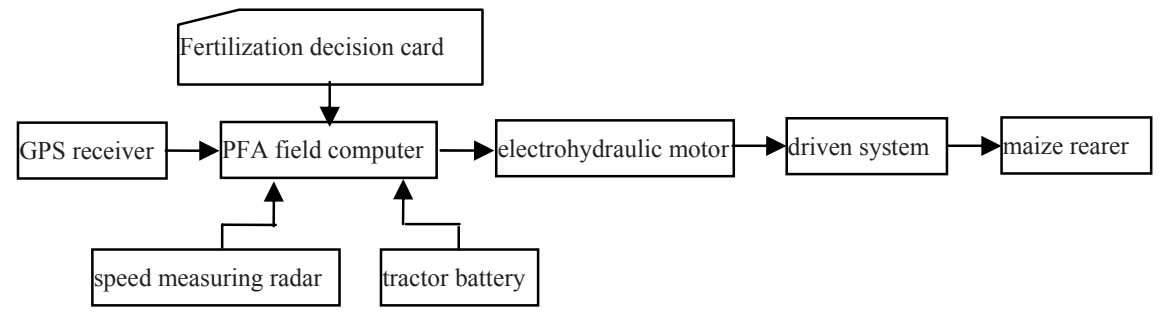

Fig. 3 The operating principle of variable rate machine

In the year 2007, precision fertilization was implemented in the experimental site.The results shows that, by precision fertilization, the maize yield was increased by nearly $10 \%$ and the fertilizer was saved about $10.5 \%$ compared with traditional fertilization mode.

\section{CONCLUSION AND DISCUSSION}

In this paper, spatial variation of soil nutrient was explored and we found that the spatial variability of $\mathrm{P}$ is the largest, which indicate that the precision fertilization of black soil area in Jilin province is dependent on the variability of P. We also analyzed the existing fertilization model and gave an 
appropriate model fitted with black soil zone. A web-based expert system for precision fertilization was developed and the precision fertilization practice was implemented. The experiment shows that the adoption of above scheme acquired good results and achieved the aim of reducing cost, lessening environmental pollution, increasing yield and improving quality.

The later study will focus on the following aspects. Firstly, the current fertilization technology convergence is not enough, which should be strengthened. Secondly, the grid plotting is based on expert experience and the sampling number is not accurate, farther experiment should be done to achieve more optimum grid layout and more accurate grid number. Thirdly, the current precision fertilization is based on single variable, namely variable rate fertilizing $\mathrm{P}$, in order to acquire more fertilization precision, dual variable rate fertilization should be considered, namely variable rate fertilizing $\mathrm{P}$ and $\mathrm{N}$.

\section{ACKNOWLEDGEMENTS}

Funding for this research was provided by National "863" project " research and application of maize precision working system " (No.2006AA10A309).

\section{REFERENCES}

CHEN Gui-fen,WANG Yue,WANG Guo-wei. Research and Application of the Maize Precise Fertilization System [J].Journal of Jilin Agricultural University.2006, 28(5):586-590.(in Chinese)

Edson Murakami,Antonia M.Saraiva,et al. An infrastructure for the development of distributed service-oriented information systems for precision agriculture[J].Computers and Electronics in agriculture. 2007(58):37-48.

GAO Xiang-zhao, HU Ke-lin,etc. Spatial Variability of Soil Nutrient s and Crop Yield and Site-specific Fertilizer Management [J].Scientia Agricultura Sinica.2002:35(6):660-666. (in Chinese)

Hou yanlin, Chen shoulun. Summarization of Fertilization Model Research [J]. Chinese Journal of Soil Science.2004,35(4):493-501. (in Chinese)

QU Gui-bao,TIAN-yun. The actualize process of variable rate fertilization an it's foreground of development[J]. Chinese agricultural mechanization .2005(4):50-52. (in Chinese)

Rodrigo A,Ortega,etc al. Determination of management zones in maize(Zea Mays L.)based on soil fertility[J]. Computers and Electronics in agriculture.2007(58):49-59.

Xie Jia-gui, Wang Li-chun, etc. High Quality Maize Response to Nitrogen, Phosphorus and Potassium [J]. Journal of Maize Sciences..2006,14(6):131-133. (in Chinese)

Zhang Shuhui, Ma Chenglin, Li We i, Xu Yan,etc. Experimental study on the influence of variable rate fertilization on maize yield and soil nutrients [J]. Transact ions of the CSA E.2006,22(8):64-67. (in Chinese) 
Zhang Shujuan, He Yong, Fang Hui. Spatial variability of soil properties in the field based on GPS and GIS [J]. Transact ions of the CSA E.2003, 19(2):39-43. (in Chinese). 